\title{
AN ANALYSIS OF THE GROWTH OF LEAF AREA OF OIL PALMS IN INDONESIA
}

\author{
By W. GERRITSMA† and F. X. SOEBAGYO \\ Bah Lias Research Station, PTPP London Sumatra Indonesia, PO Box 1154, \\ Medan 20111, Indonesia
}

(Accepted 18 December 1998)

\begin{abstract}
SUMMARY
In two cultivar $\times$ density trials for oil palms (Elaeis guineensis) planted in Indonesia, single leaf area, number of green leaves per tree, leaf opening rate per year and rachis length of leaves were followed over fourteen years. The data were analysed to determine the time course of canopy leaf area and to predict the moment of canopy closure.

Growth functions were fitted to the observed data. Estimates of leaf area index $(L)$ were based on single leaf area, number of green leaves, leaf opening and planting density. The time course of $L$ was modelled on the basis of the fitted functions to the components. The moment of canopy closure was calculated from the planting density and the functions fitted for rachis length.

The modelled time course of $L$ was considerably different from the function fitted to the single leaf area data. The expansion of $L$ was not as rapid as expected from the area growth of single leaves and, after maximum $L$ was reached, a steady decline was observed. The continuously declining number of green leaves was the main cause of these two observations.

The time course of $L$ differed considerably between the two experiments. Not only were there large differences in the number of green leaves maintained per tree in the experiments but also the final area of single leaves differed between both experiments. The first factor was a result of the management of the experiments, whereas the second factor was most likely influenced by a difference in soil-related factors at the two locations.

Leaf areas and numbers of leaves per tree were different for each cultivar, as was $L$. This was also the parameter most sensitive to planting density. Individual leaf area and leaf number per tree were not affected by planting density, but rachis length was affected by the planting density treatment. The moment of canopy closure was similar in both experiments. Planting density was the main factor that determined the onset of canopy closure.
\end{abstract}

\section{INTRODUGTION}

The shape and leaf area of crowns determine light interception and thus influence yield of oil palms (Elaeis guineensis Jacq.) (Hardon et al., 1969; Corley, 1973; Breure, 1985). The analysis of the time course of the components of canopy leaf area, other than the surface area of individual leaves, has received relatively little attention in oil palm research.

The morphology, growth and development of oil palm leaves were described by Yampolski (1922), Henry (1957) and Gray (1969). Leaf primordia are produced at regular intervals by the single, terminal growing point of the palm. Three stages

†Current address: Wageningen Agricultural University, Department of Crop Science, Haarweg 333, 6709 RZ Wageningen, The Netherlands. Email: wouter.gerritsma@users.agro.wau.nl 
in the development of leaves are recognized: an initial period of slow growth and development followed by a second phase of rapid elongation. The leaf opens only when it has attained its full size and then the third phase of assimilate production starts. The surface area of the leaf remains unaltered once it has fully opened. Each newly opened leaf is larger than the previous leaf until the final leaf area reaches the maximum value. The area of fully opened leaves is influenced by palm age, the type of planting material and growing conditions (Hardon et al., 1969; Breure, 1985).

The canopy leaf area, expressed as leaf area index $(L)$, is also determined by the planting density of the palms and the number of green leaves per palm. The planting density is fixed, but after a certain age a decline in the stand density is usually observed. Studies of the decline in stand density with age of oil palm plantings are rare, and were not the subject of this investigation. The number of green fronds per tree has not yet been studied systematically. In most oil palm growth studies estimation of the number of green fronds is based on experience rather than actual observations (Squire, 1986; Breure, 1988).

The number of green leaves per tree is the result of two antagonistic processes: leaf opening and leaf removal. The number of leaves opening per year declines with the age of the trees (Corley and Gray, 1976; Breure, 1988). The yearly leaf opening rate is further affected by planting density, annual rainfall and soil fertility (Breure, 1988; Broekmans, 1957; Corley and Mok, 1972). Removal of old leaves takes place during harvesting of fruit bunches when a few leaves supporting the fruit bunch are removed. In younger palms fewer leaves are removed with harvesting than in older and taller palms. Regular pruning is carried out as part of the standard estate management and upkeep routines, since old leaves adhere to the palm and obstruct the routine harvesting procedures. With cultivated oil palm, leaf removal is thus mainly a management operation rather than a natural process.

The occurrence of gaps, the overlap between neighbouring palm crowns and the moment of canopy closure, also affect light interception of oil palm canopies. The radius of the crown in relation to the planting distance and pattern of the trees largely determines the onset of canopy closure. Crown radius itself depends on leaf length. In most oil palm experiments rachis length rather than leaf length is measured, since measuring petiole length of the younger leaves is difficult. Rachis and petiole lengths are highly correlated with each other (Henry, 1957; Lecoustre and Jaeger, 1989). Leaf length increases with the age of the trees until the maximum length is reached. The maximum length of oil palm leaves is strongly affected by planting density and planting material (Breure, 1982; Rao et al., 1992).

The objective of this study was to determine the time course of leaf area index and closure of oil palm canopies. The leaf area, number of green leaves, leaf opening rate and rachis length were analysed in two identical density $\times$ cultivar experiments planted at two locations in North Sumatra. The two experiments allowed the determination of spacing and cultivar effects on the components of 
leaf area index and the closure of oil palm canopies. Comparison of the two experiments provided an opportunity to look into the influence of growing conditions on these characteristics.

\section{MATERIALS AND METHODS}

\section{Experiments}

The experiments were two identical cultivar $\times$ density trials planted at different estates in 1979. Experiment 1 was laid down at the Bah Lias Estate $\left(\right.$ lat $3^{\circ} 11^{\prime} \mathrm{N}$, long $99^{\circ} 20^{\prime} \mathrm{E}$ ), which has a relatively low annual rainfall (10-year average $1663 \mathrm{~mm} \mathrm{a}^{-1}$ ) and an average daily short-wave radiation of $16.7 \mathrm{MJ} \mathrm{m}^{-2} \mathrm{~d}^{-1}$. Experiment 2 was at the Gunung Melayu Estate (lat $2^{\circ} 48^{\prime} \mathrm{N}$, long $99^{\circ} 34^{\prime} \mathrm{E}$ ), which receives more evenly distributed annual rainfall (10-year average $2460 \mathrm{~mm} \mathrm{a}^{-1}$ ), and a similar amount of radiation, averaging $16.8 \mathrm{MJ} \mathrm{m}^{-2} \mathrm{~d}^{-1}$. The soils are old volcanic soils classified as yellow red podsolic with a sandy clay-loam texture. The soils are more fertile at Bah Lias (H. L. Foster, personal communication).

The experiments were designed as split-plot, with planting density as the main treatment and the cultivars as the sub-treatments, with five replications. In each replicate the planting densities were laid down as strip-plots. Each plot was divided into three subplots where the three cultivars were planted. The cultivars in each replicate were laid down according to a $3 \times 3$ Latin square design. In each plot 48 palms were planted ( 6 rows of 8 palms) of which only the data from the 24 core palms (4 rows of 6 palms) were analysed. The planting densities were 128, 143 and 160 palms ha $^{-1}$ at which three Deli dura $\times$ pisifera $(\mathrm{D} \times \mathrm{P})$ cultivars were compared. Cultivar 1 was of Papua New Guinean D $\times$ P origin, Cultivar 2 was Gunung Melayu dura $\times$ local pisifera (Rosenquist, 1986) and Cultivar 3 was commercial Marihat $\mathrm{D} \times \mathrm{P}$ material (Lubis, 1984).

\section{Observations}

Each year the surface area of the most recently opened leaf was measured and, in November (leaf 1), was marked according to the method of Hardon et al. (1969) where the average length and width of the six longest leaflets are related to the leaf area. This procedure started in the third year after field planting (YAP). Rachis length and petiole cross-section $\left(P_{\mathrm{cs}}\right)$ of the same leaf were measured according to the methods developed by Corley and Breure (1981). $P_{\mathrm{cs}}$ measurements of the leaf marked in November were already available from 1 YAP and these observations were used to estimate the area of leaves in 1 and 2 YAP. A linear relationship determined from measurements on leaves in two- to six-year-old oil palm plantings served this purpose. Rachis length was only available from 4 YAP. The number of green leaves on each palm was recorded three times per year. For this analysis the results were averaged annually from the second year onwards. The leaf opening rate was recorded at half-yearly intervals in the early part of the experiment, but subsequently when the leaf opening rate declined, records were taken at yearly intervals. 


\section{Leaf area index}

The $L$ was calculated from the average leaf area per palm, the number of green leaves per tree and the planting density. The average leaf area per palm in a year was calculated from the surface area of leaves marked in the current year and the previous year, using a correction for the leaf opening rate and the number of green leaves on the tree. This ratio of green leaves over leaf opening has its main effect on average leaf area in the phase of rapid leaf expansion.

$$
\bar{l}=l_{\mathrm{i}}-\frac{\mathcal{N}\left(l_{\mathrm{i}}-l_{\mathrm{i}-1}\right)}{2 F}
$$

where $\bar{l}$ is the average leaf area, $l_{\mathrm{i}}$ the area of the leaf marked in the current year, $l_{\mathrm{i}-1}$ the area of the leaf marked in the previous year, $\mathcal{N}$ is the number of green leaves per tree and $F$ is the number of leaves opened between the marked leaves.

\section{Analysis}

Area and rachis length of the most recently opened leaf, number of leaves opened each year and number of green leaves per tree were analysed for the influence of density or cultivar treatment each year separately (Anon, 19821993). For this investigation non-linear, asymptotic, three-parameter functions were fitted to the data for leaf area, leaf opening rate and rachis length, using the SAS (1985) NLIN procedure. The functions were fitted to the data for each subplot separately. The most suitable type of function was selected using the smallest average residual sum of squares as a criterion. For the number of green leaves per tree, linear regression equations were used. The parameters obtained for each subplot were then used in an analysis of variance for a split-plot experiment with allowance for the Latin-square design (Keen et al., 1989). The time course for $L$ was then modelled using the functions for leaf area, number of green leaves and leaf opening rate. The modelled time course was compared with the observed $L$.

Canopy closure is defined as the onset of overlap between three neighbouring crowns and was estimated from the growth functions for the rachis. The leaf length was calculated as 1.25 times the rachis length (Gray, 1969; Lecoustre and Jaeger, 1989). The crown radius was approximated using the calculated leaf length, the effect of leaf arching was not accounted for explicitly in this approximation. Since the palms were planted in equilateral triangles, canopy closure could be calculated from the planting density and approximate crown radius.

\section{RESULTS}

Relation between petiole cross section and leaf area

A relation between the petiole cross section $\left(P_{\mathrm{CS}}\right)$ and single leaf area was 
determined in 1988 on leaves from fields differing in age from 2 to 6 YAP. In each age group full-grown leaves (leaf 30) were harvested and the area and $P_{\mathrm{cs}}$ determined. The following regression fitted the observations between leaf area $l$ and $P_{\mathrm{cs}}$ :

$$
l=0.35+0.30 P_{\mathrm{cs}} \quad \mathrm{R}^{2}=0.82 \quad \text { d.f. }=48
$$

$P_{\mathrm{cs}}$ (width $\times$ depth) is expressed in $\mathrm{cm}^{2}$ and $l$ is the estimated leaf area in $\mathrm{m}^{2}$ leaf $^{-1}$. This relation was used to convert the $P_{\mathrm{cs}}$ observations of the first two YAP to estimates of leaf area in both experiments.

\section{Area of the youngest leaf}

The area of the leaf marked in November each year increased until 10 and 11 YAP in Experiments 1 and 2 respectively (Fig. 1). Except for the dip in leaf area at 11 YAP the leaf area remained virtually constant after it reached the maximum size in Experiment 1. In Experiment 2 more variation was observed in the leaf area after the maximum size was attained. Differences in the area of the youngest leaf between the experiments were initially small, but from the 8 YAP leaves in Experiment 1 were larger than in Experiment 2.

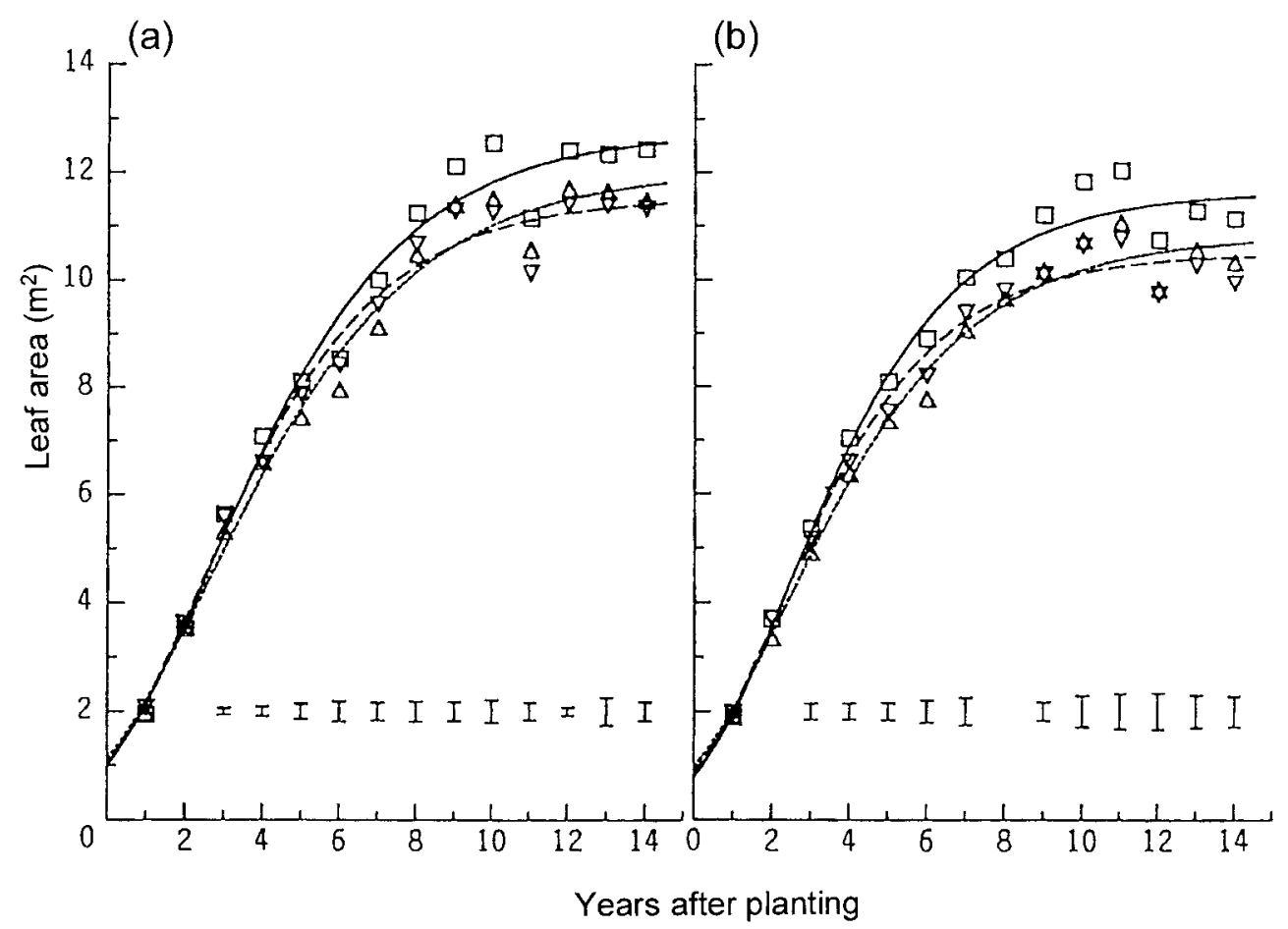

Fig. 1. Growth of leaf area of oil palms at sites $1(a)$ and $2(b)$, and the fitted Gompertz functions for Cultivar $1(\square,-)$, Cultivar $2(\triangle, \cdots \cdots)$ and Cultivar $3(\nabla,----)$. Bars indicate l.s.d. at $p<1 \%$. 
Table 1. Parameters for the Gompertz functions $\gamma=\alpha \mathrm{e}^{-\beta \mathrm{e}^{-\gamma \mathrm{t}}}$ fitted to the leaf area data for oil palms where $Y$ is the area of the leaf $\left(\mathrm{m}^{2}\right)$ and $t$ is time in years after field planting (YAP).

\begin{tabular}{|c|c|c|c|c|}
\hline & & $\alpha\left(\mathrm{m}^{2}\right)$ & $\beta(-)$ & $\gamma\left(\mathrm{YAP}^{-1}\right)$ \\
\hline \multicolumn{5}{|c|}{ Experiment 1} \\
\hline \multirow{3}{*}{ Density (palms ha ${ }^{-1}$ ) } & 160 & 12.19 & 2.48 & 0.36 \\
\hline & 143 & 12.13 & 2.47 & 0.36 \\
\hline & 128 & 11.99 & 2.44 & 0.35 \\
\hline L.s.d. $(p<1 \%)$ & & NS & NS & NS \\
\hline \multirow[t]{3}{*}{ Cultivar } & 1 & 12.74 & 2.56 & 0.35 \\
\hline & 2 & 12.03 & 2.38 & 0.33 \\
\hline & 3 & 11.53 & 2.46 & 0.38 \\
\hline L.s.d. $(p<1 \%)$ & & 0.35 & 0.12 & 0.02 \\
\hline \multicolumn{5}{|c|}{ Experiment 2} \\
\hline \multirow[t]{3}{*}{ Density (palms ha ${ }^{-1}$ ) } & 160 & 10.96 & 2.58 & 0.41 \\
\hline & 143 & 10.80 & 2.55 & 0.40 \\
\hline & 128 & 11.15 & 2.53 & 0.40 \\
\hline L.s.d. $(p<1 \%)$ & & NS & NS & NS \\
\hline \multirow[t]{3}{*}{ Cultivar } & 1 & 11.63 & 2.70 & 0.41 \\
\hline & 2 & 10.81 & 2.42 & 0.37 \\
\hline & 3 & 10.47 & 2.53 & 0.43 \\
\hline L.s.d. $(p<1 \%)$ & & 0.58 & 0.12 & 0.03 \\
\hline
\end{tabular}

The cultivar treatment resulted in significant differences from 3 YAP in both experiments, with the exception of 8 YAP in Experiment 2. The leaf area was always largest for Cultivar 1. At the beginning of the experiment Cultivar 2 had the smallest leaf area but towards the end of the observed period Cultivar 3 had the smallest leaf area. Differences in leaf area due to the density treatment did not result in significant differences in any year in either experiment. The responses with respect to cultivar and density treatments were similar in both experiments.

Gompertz functions gave the best fit to the data in both experiments. Of the treatment effects, only cultivars affected all three parameters of the functions significantly; differences due to the density treatment failed to reach significance (Table 1). The final leaf area in Experiment 1, as expressed by parameter $\alpha$, was a full $\mathrm{m}^{2}$ larger than observed in Experiment 2. The initial areas as expressed by parameters $\alpha$ and $\beta$ were similar in both experiments. The rate of change in the area of leaves between years, expressed by parameter $\gamma$, was larger in Experiment 2 than Experiment 1.

\section{Number of green leaves per palm}

From 3 to 14 YAP a continuous decline in the number of green leaves per palm was observed. Variation in number of green leaves per tree between years was large, especially during the first seven years in Experiment 2 (Fig. 2). At the beginning of the experiments, fewer leaves were maintained per palm in Experi- 
(a)

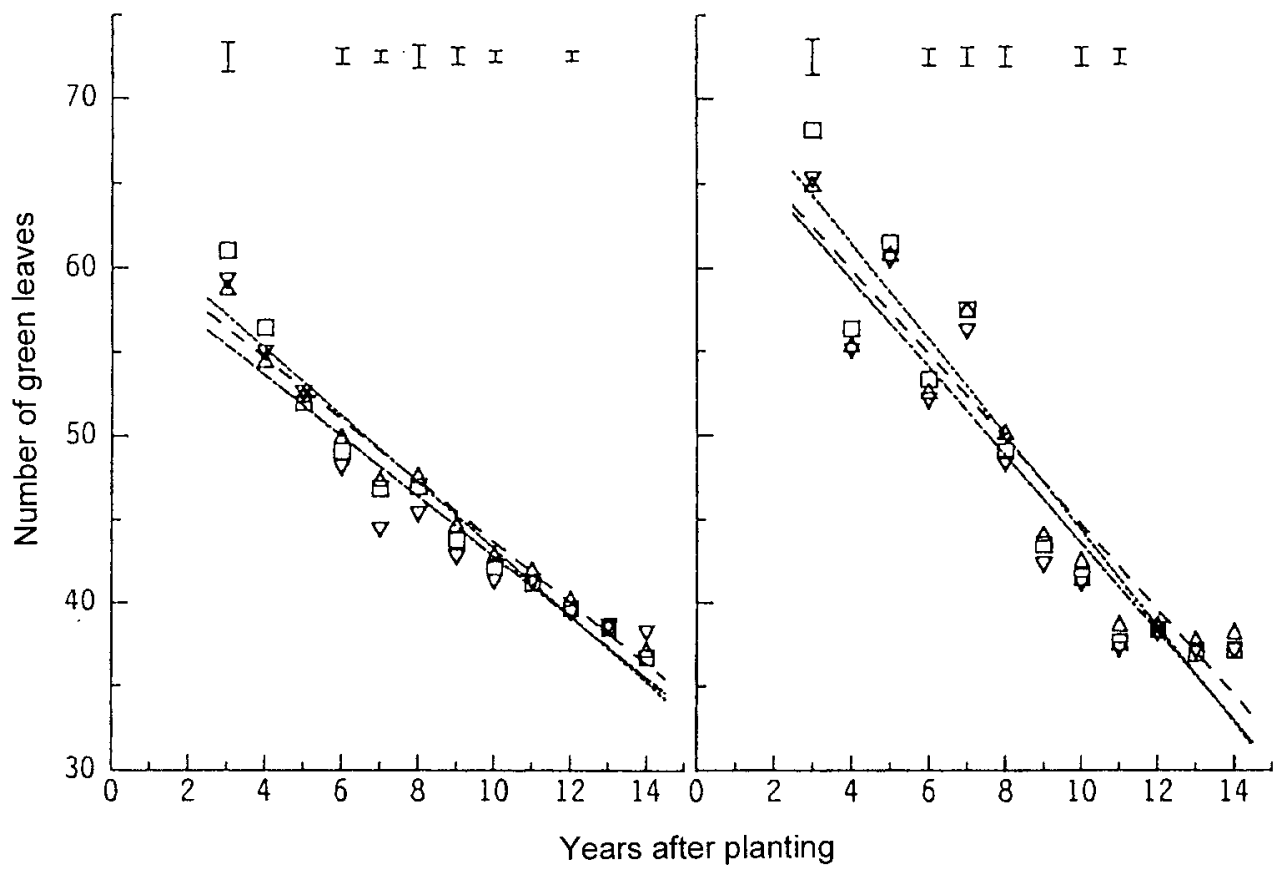

Fig. 2. Numbers of green leaves of oil palms at sites 1 (a) and 2(b) and the linear regression functions for Cultivar $1(\square, \longrightarrow)$, Cultivar $2(\triangle, \cdots \cdots)$ and Cultivar $3(\nabla,----)$. Bars indicate 1.s.d. at $p<1 \%$.

ment 1 than in Experiment 2, notwithstanding managerial efforts put into the standardization of husbandry practices at both sites. Differences due to the cultivar treatment in each experiment were significant in most years until 12 YAP (Fig. 2). Only in a few years did the density treatment result in significant difference between treatments (data not shown).

Several growth functions were tried, but none of these really fitted the observed trend of declining numbers of green leaves with tree age, notwithstanding the apparent stabilization of green leaves per tree after 10 YAP in Experiment 2. The decline observed could best be described with linear relationships between the green leaves per tree and ages of the trees. Differences in intercepts and slopes were significant for the cultivar treatment in both experiments, but not for the density treatment (Table 2). The intercepts of the lines were lower and the slopes less steep in Experiment 1 compared with Experiment 2.

\section{Leaf opening rate}

The leaf opening rate showed a decreasing decline over the course of the experiments. Very similar rates of leaf opening were observed at the beginning in both experiments. Differences in leaf opening rate between the experiments started to show up from 10 YAP onwards, when in Experiment 1 one extra leaf per tree per year opened compared with Experiment 2. 
Table 2. Parameters for the linear functions $r=\alpha+\beta t$ between green leaves per tree with age for oil palms, where $\alpha$ is the onset of the line (leaves) and $\beta$ is the slope of the line (leaves $\mathrm{a}^{-1}$ ).

\begin{tabular}{lccc}
\hline & & $\alpha(-)$ & $\beta\left(\mathrm{a}^{-1}\right)$ \\
\hline & Experiment 1 & \\
Density $\left(\right.$ palms ha $\left.^{-1}\right)$ & 160 & 62.6 & -2.0 \\
& 143 & 61.8 & -1.9 \\
& 128 & 61.6 & -1.8 \\
L.s.d. $(p<1 \%)$ & & $\mathrm{NS}$ & $\mathrm{NS}$ \\
& & & \\
Cultivar & 1 & 63.2 & -2.0 \\
& 2 & 61.9 & -1.8 \\
L.s.d. $(p<1 \%)$ & 3 & 60.8 & -1.8 \\
& & 1.3 & 0.2 \\
Density $\left(\right.$ palms ha $\left.{ }^{-1}\right)$ & 160 & 70.1 & -2.6 \\
& 143 & 71.7 & -2.7 \\
L.s.d. $(p<1 \%)$ & 128 & 70.6 & -2.7 \\
Cultivar & & $\mathrm{NS}$ & $\mathrm{NS}$ \\
& & & \\
L.s.d. $(p<1 \%)$ & 1 & 72.5 & -2.8 \\
& & 70.1 & -2.5 \\
& & 69.8 & -2.6 \\
& & 1.6 & 0.14 \\
\hline
\end{tabular}

Both planting density and cultivar type affected the number of opened leaves in various years in both experiments. Cultivar type had a small but significant effect in some years until 8 YAP (Fig. 3). Cultivar 1 maintained a higher leaf opening rate than the other cultivars in those years. Density effects were significant in most years from 9 YAP in Experiment 1, whereas this occurred from 6 YAP in Experiment 2. The higher density treatment showed a significantly lower leaf opening rate in those years (data not shown).

The decline in leaf opening rate was best described by a three-parameter exponential function. Differences in parameters between experiments and treatments were not consistent between the experiments (Table 3). In Experiment 1 parameter $\alpha$, the asymptotic value for the final leaf opening rate, was significantly different for the different treatment densities and for the cultivar treatments, but not in Experiment 2. The onset of the functions as determined by parameter $\beta$ was significantly affected by both treatments in Experiment 2, but not in Experiment 1. Parameter $\gamma$, which determined the curvature of the lines, was significantly different for cultivar types in both experiments.

\section{Leaf area index}

The maximum leaf area index $L$ was reached at $10 \mathrm{YAP}$ in Experiment 1 and at 


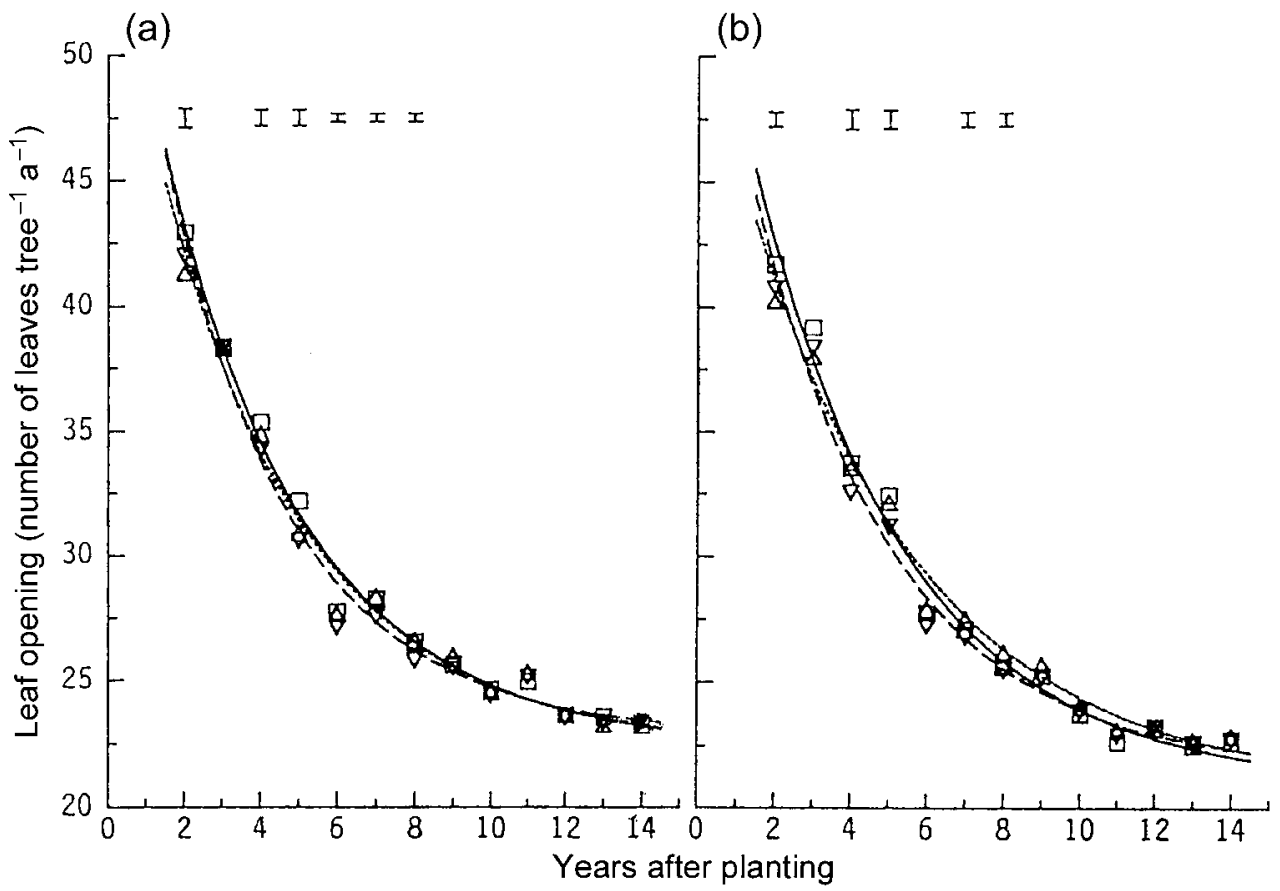

Fig. 3. Leaf opening rates of oil palms at sites $1(\mathrm{a})$ and $2(\mathrm{~b})$, and the three parameter exponential functions for Cultivar $1(\square,-)$, Cultivar $2(\triangle, \cdots \cdots)$ and Cultivar $3(\nabla,----)$. Bars indicate l.s.d. at $p<1 \%$.

Table 3. Parameters for the exponential $\gamma=\alpha\left(1+\beta \mathrm{e}^{-\gamma t}\right)$ functions fitted to the leaf opening rate data for oil palms, where $Y$ is the leaf opening rate (leaves $\mathrm{a}^{-1}$ ) and $t$ is the time (YAP).

\begin{tabular}{|c|c|c|c|c|}
\hline & & $\alpha\left(\right.$ leaves $\left.\mathrm{a}^{-1}\right)$ & $\beta(-)$ & $\gamma\left(\mathrm{YAP}^{-1}\right)$ \\
\hline \multicolumn{5}{|c|}{ Experiment 1} \\
\hline \multirow[t]{3}{*}{ Density (palms ha ${ }^{-1}$ ) } & 160 & 21.93 & 1.60 & 0.27 \\
\hline & 143 & 22.48 & 1.50 & 0.27 \\
\hline & 128 & 23.32 & 1.57 & 0.30 \\
\hline L.s.d. $(p<1 \%)$ & & 0.83 & NS & NS \\
\hline \multirow[t]{3}{*}{ Cultivar } & 1 & 22.45 & 1.59 & 0.27 \\
\hline & 2 & 22.35 & 1.49 & 0.26 \\
\hline & 3 & 22.92 & 1.58 & 0.30 \\
\hline \multicolumn{2}{|l|}{ L.s.d. $(p<1 \%)$} & 0.41 & NS & 0.02 \\
\hline \multicolumn{5}{|c|}{ Experiment 2} \\
\hline \multirow[t]{3}{*}{ Density (palms ha $\left.{ }^{-1}\right)$} & 160 & 20.52 & 1.71 & 0.25 \\
\hline & 143 & 21.28 & 1.56 & 0.24 \\
\hline & 128 & 21.69 & 1.51 & 0.25 \\
\hline L.s.d. $(p<1 \%)$ & & NS & 0.06 & NS \\
\hline \multirow[t]{3}{*}{ Cultivar } & 1 & 21.00 & 1.70 & 0.25 \\
\hline & 2 & 20.92 & 1.50 & 0.22 \\
\hline & 3 & 21.58 & 1.59 & 0.27 \\
\hline L.s.d. $(p<1 \%)$ & & $\mathrm{NS}$ & 0.13 & 0.03 \\
\hline
\end{tabular}


(a)

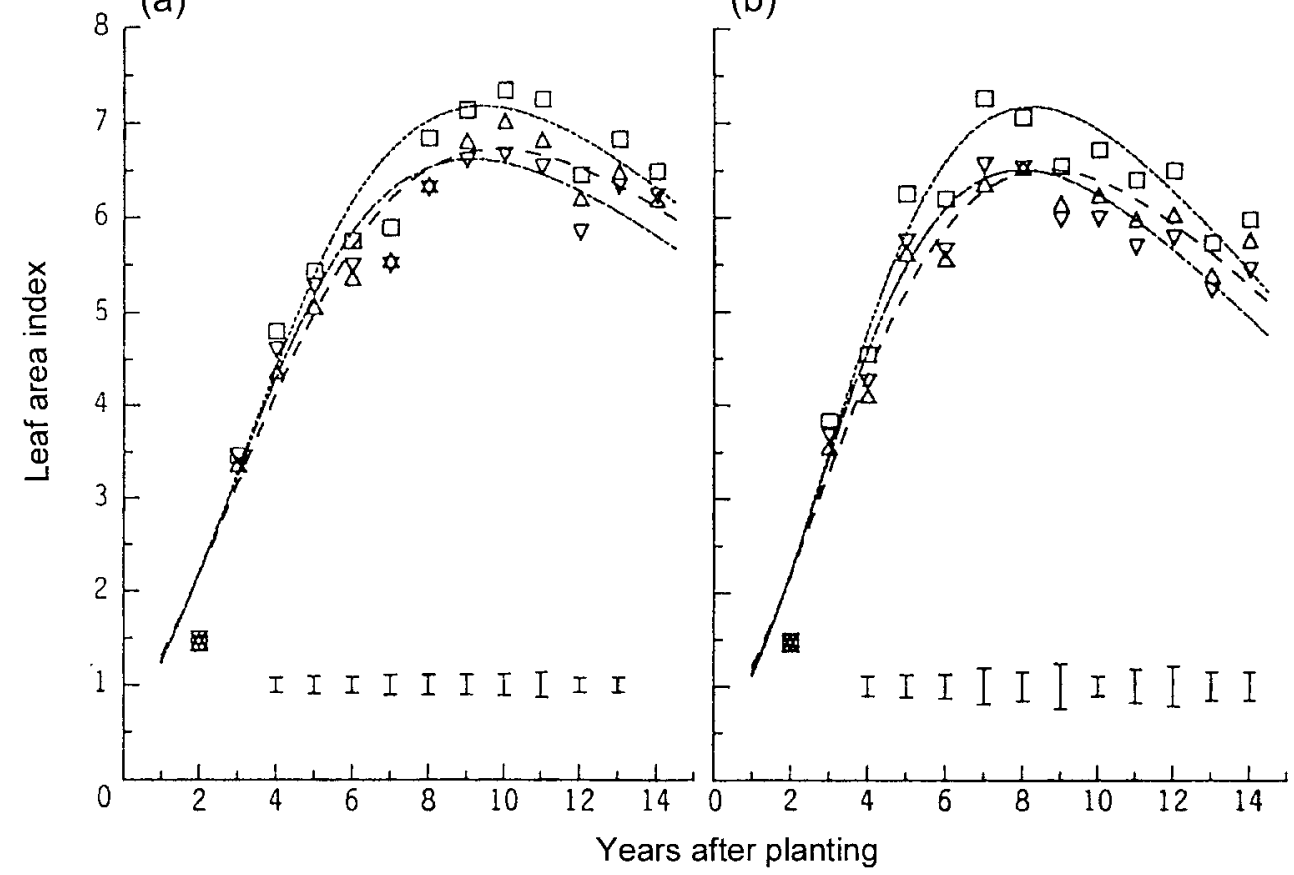

Fig. 4. Mean leaf area indices of oil palms averaged over planting densities at site 1 (a) and 2(b), and the modelled curves for Cultivar $1(\square,--$, Cultivar $2(\triangle, \cdots \cdots)$ and Cultivar $3(\nabla,----)$. Bars indicate l.s.d. at $p<1 \%$.

8 YAP in Experiment 2. After the maximum was reached, $L$ decreased again. The decline in $L$ was smaller in Experiment 1 than Experiment 2 (Fig. 4).

Both cultivar and density treatments resulted in significant differences for $L$ in nearly all years in both experiments. $L$ was highest at the 160 palms ha $^{-1}$ density and was smaller at the lower planting densities, as was to be expected. With respect to cultivar differences, Cultivar 1 had significantly larger $L$ values in most years compared with the other two cultivars. The ranking of Cultivars 2 and 3 changed during the experiment. Cultivar 2 was the smallest at the onset of the experiment, but later Cultivars 2 and 3 changed in their ranking. This trend was similar to the trend observed with single leaf areas.

There are no simple growth functions available to describe the time course of $L$ growth. Since $L$ is a function of average leaf area, number of green leaves and planting density the time course could be modelled from the functions fitted to the separate components (Fig. 4). The modelled time courses reached their optimum around 9 YAP in Experiment 1 and 8 YAP in Experiment 2, and showed a decline until 14 YAP.

\section{Leaf length}

The length of the rachis increased until 10 YAP in both experiments. Before 4 


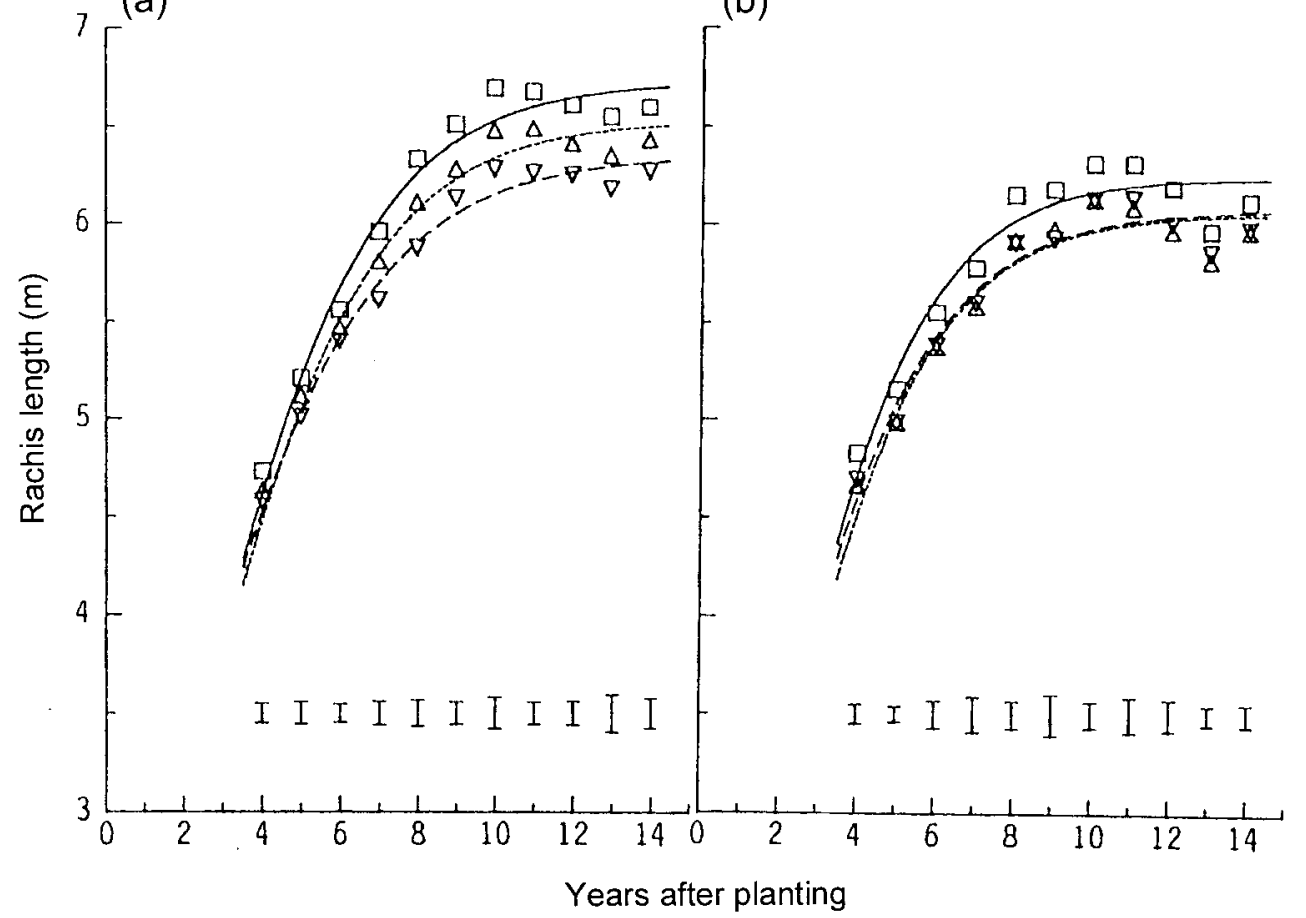

Fig. 5. Growth of rachis length of oil palms at site $1(\mathrm{a})$ and 2(b), and the fitted logistic functions for high $(\square,-)$, medium $(\triangle, \cdots \cdots)$ and low $(\nabla,----)$ planting densities. Bars indicate 1.s.d. at $p<1 \%$.

YAP no observations on rachis length were made. After the period of expansion, there was still a slight decrease in rachis length (Fig. 5).

In each year significant differences in rachis length due to both the density and cultivar treatments were observed in both the experiments. The rachis length was always significantly longer at the higher planting density. With respect to the cultivar differences, Cultivar 3 was significantly shorter in the second half of the observation period in Experiment 1. The leaves of Cultivar 1 were significantly longer than those of the other two cultivars over the whole observation period in Experiment 2 (data not shown).

The trend in rachis length expansion was best described with a logistic function. The parameter values for the fitted functions are presented in Table 4. With respect to the density treatment, the functions differed significantly from each other in the asymptotic value. For the cultivars, significant differences in the asymptotic values were observed as well, but also in $\gamma$ in both experiments, and in the parameter $\beta$ in Experiment 2.

Based on the fitted functions for rachis length the onset of canopy closure could be approximated from the planting distance and estimated leaf length. The approximate time of canopy closure is indicated in Table 4. Canopy closure occurred before rachis length measurements began. The planting density resulted in significant differences in the onset of canopy closure between the treatments, 
Table 4. Parameters for the logistic functions $R=\frac{\alpha}{1+\beta \mathrm{e}^{-\gamma t}}$ fitted to the rachis length data for oil palms where $R$ is the rachis length $(\mathrm{m})$ and $t$ the time (YAP). The last column gives the onset of canopy closure $\mathrm{T}_{\mathrm{c}}(\mathrm{YAP})$.

\begin{tabular}{|c|c|c|c|c|c|}
\hline & & $\alpha(\mathrm{m})$ & $\beta(-)$ & $\gamma\left(\mathrm{YAP}^{-1}\right)$ & $\mathrm{T}_{\mathrm{c}}(\mathrm{YAP})$ \\
\hline \multicolumn{6}{|c|}{ Experiment 1} \\
\hline \multirow[t]{3}{*}{ Density $\left(\right.$ palms ha $\left.^{-1}\right)$} & 160 & 6.73 & 2.77 & 0.45 & 2.96 \\
\hline & 143 & 6.53 & 2.77 & 0.45 & 3.33 \\
\hline & 128 & 6.35 & 2.16 & 0.42 & 3.71 \\
\hline L.s.d. $(p<1 \%)$ & & 0.14 & NS & NS & 0.24 \\
\hline \multirow[t]{3}{*}{ Cultivar } & 1 & 6.66 & 2.62 & 0.45 & 3.28 \\
\hline & 2 & 6.59 & 2.33 & 0.41 & 3.40 \\
\hline & 3 & 6.36 & 2.75 & 0.48 & 3.33 \\
\hline \multicolumn{2}{|l|}{ L.s.d. $(p<1 \%)$} & 0.12 & NS & 0.04 & NS \\
\hline \multicolumn{6}{|c|}{ Experiment 2} \\
\hline \multirow{3}{*}{ Density (palms ha ${ }^{-1}$ ) } & 160 & 6.25 & 2.95 & 0.55 & 2.85 \\
\hline & 143 & 6.07 & 2.77 & 0.52 & 3.28 \\
\hline & 128 & 6.09 & 2.40 & 0.50 & 3.60 \\
\hline L.s.d. $(p<1 \%)$ & & 0.13 & NS & NS & 0.10 \\
\hline \multirow[t]{3}{*}{ Cultivar } & 1 & 6.27 & 3.18 & 0.56 & 3.21 \\
\hline & 2 & 6.12 & 1.97 & 0.43 & 3.25 \\
\hline & 3 & 6.01 & 2.96 & 0.57 & 3.27 \\
\hline L.s.d. $(p<1 \%)$ & & 0.13 & 0.95 & 0.09 & NS \\
\hline
\end{tabular}

whereas the cultivar treatment did not affect the onset of canopy closure. Higher planting density led to significantly earlier canopy closure. In both experiments canopy closure occurred at the highest planting density 10 months earlier than at the lowest planting density.

\section{DISGUSSION}

In young plantings leaf area could be estimated from observations of petiole crosssection area. At older ages the relation was no longer valid because of competition effects between palms which altered the ratio between leaf area and $P_{\mathrm{cs}}$. It was thus possible to estimate leaf area from $P_{\mathrm{cs}}$; however, in this study the relation was only used for the first two YAP because for the other ages leaf area was measured. The possibility that the relationship between $P_{\mathrm{cs}}$ and leaf area could vary between cultivars was not a subject of this investigation.

A first use of growth functions in oil palm experiments was made by Phang et al. (1977). They studied the progression of leaf dry weight and leaf area of oil palms planted on different soil series to predict the early yields of those plantings. Subsequent use of growth functions for leaf area data was made by Breure (1985) to define additional selection criteria in oil palm breeding. Neither Phang et al. (1977) nor Breure (1985) tested growth functions other than a logistic one. In this study it was found that a Gompertz rather than a logistic function best described 
the trend in area of the youngest fully opened leaf with time. The trend in leaf opening rate with time was best described by a three-parameter exponential function, whereas the rachis length data were best described using a logistic function. The shape of these functions are all different from each other, for example, the Gompertz function has a point of inflexion occurring at one-third of the maximum $\mathrm{Y}$ value compared with half for the logistic function. From this analysis it appeared that selecting the right type of functions is an important step in the growth analysis. This is of special importance when function parameters are used for management decisions or in breeding as was proposed by Phang et al. (1977) and Breure (1985) respectively.

All three parameters of the functions fitted to the leaf area data differed significantly from each other for cultivar type but not for density treatment. This was in line with the analyses that were carried out each year to compare the treatment influences on the area of most recently opened leaf. The influence of cultivar type on the parameters of the curve supports the idea of Breure (1985) that cultivar types exhibit different patterns of leaf area expansion. Cultivars 1 and 3 both expanded rapidly in the first years after planting, but they attained different maximum values. Cultivar 2 expanded more slowly compared with the other two cultivars, but reached a larger final leaf area than Cultivar 3. The maximum leaf area fitted for these experiments, $11.0-12.5 \mathrm{~m}^{2}$, are in line with the maximum leaf area fitted by Breure (1985) for oil palms planted in Papua New Guinea.

The trend in number of green leaves per tree with time showed a constant decline. The data were not sufficient to define curves other than simple linear regressions to describe this trend. In Experiment 2 a plateau seemed to be reached in the last four years, but the highly variable observations until 9 YAP made it difficult to select a function other than a linear one. Extrapolation of the fitted lines for number of green leaves per tree beyond 14 YAP did not seem reliable. Despite the effort put into the standardization of management practices in both experiments the data showed that the pruning and harvesting routines in both experiments resulted in substantial differences in the numbers of green leaves per tree. So far little attention has been paid to the number of green leaves per palm in oil palm research. In most cases the number of green leaves was estimated based on observations in commercial blocks (Hardon et al., 1969; Squire, 1986; Breure, 1988). The results presented here indicated that estimates of the number of green leaves per tree can differ a great deal between years and experiments, especially up to 10 YAP.

The rapid increase in $L$ in the first years after planting was largely due to the growth in leaf area of the most recently opened leaf. The leaf area growth was larger than required to compensate for the decline in the number of green leaves per palm. At nine YAP in Experiment 1, and eight YAP in Experiment 2, the rate of growth in leaf area became too small to compensate for the ever decreasing number of green leaves per tree and $L$ decreased as a result. The earlier and more rapid decrease in $L$ in Experiment 2 was the result of the faster decline in the number of green leaves per tree in this experiment compared with Experiment 1. 
Another reason why the $L$ curve did not run parallel with the leaf area curve was that the average leaf area per crown is a more conservative characteristic than the area of the most recently opened leaf. When the number of green leaves per tree stabilizes, $L$ also stabilizes as a result. Since the time course of $L$ depends upon the number of green leaves as well as the area per leaf, extrapolation of $L$ based on single leaf area data alone and assumptions about the number of green leaves can lead to erroneous results (Hardon et al., 1969; Squire, 1986; Breure, 1988). Moreover, the increased light penetration observed in older oil palm plantings (Breure, 1988) is partly explained by the reduction in $L$ observed in these experiments.

Based on the functions for rachis length data and planting densities, the point of canopy closure, that is, the time when the crowns of three neighbouring palms started to overlap, could be approximated. Bending of leaves will have a small influence on this approximation but is not likely to invalidate the results. Rachis length was the parameter most sensitive to planting density. Higher planting densities resulted in significantly longer leaves, without a change in the surface area of those leaves. The decrease in $L$ that was observed in both experiments at nine YAP resulted in reduced interpalm competition as measured by the rachis length in Experiment 1. However, this was less clear in Experiment 2. In Experiment 1 the response to planting density was also more pronounced than in Experiment 2, where rachis lengths at the medium and low planting densities were very similar. It appears that rachis length is more sensitive to interpalm competition than leaf area itself. The latter was suggested as an indicator of interpalm competition by Corley et al. (1973).

The growing conditions in Experiment 1 appeared to be more favourable than in Experiment 2. This was best reflected by the larger leaf areas, longer rachis lengths and faster leaf opening rates observed during the second half of Experiment 1. In the first half of the observation period the difference in these parameters between Experiments 1 and 2 were small, the only difference between the experiments then was caused by the different number of green leaves in both experiments. As a result, the maximum $L$ was reached earlier in Experiment 2 than in Experiment 1. However, the less favourable growing conditions resulted in a more rapid decline of $L$. It was hypothesized that favourable growing conditions were concerned with soil-related factors, since the weather conditions as characterized by radiation and rainfall were more favourable at Location 2 than at Location 1. Corley and Mok (1972) showed that better soil fertility resulted in larger leaves.

Growth functions were used to utilize the data collected in a single analysis; this provided additional information to the yearly analyses. The growth functions made it easier to establish trends and to make comparisons between the experiments since yearly fluctuations were smoothed. Furthermore, it was demonstrated that the trend in $L$ did not parallel the trend in area of the youngest fully expanded leaf, mainly because the number of green leaves declined steadily over the observation period. The observed decline in $L$ made it necessary to reconstruct 
the time course from the components rather than fitting a curve to the $L$ data directly. The modelled time course of $L$ can be used in the calculation of light interception and photosynthetic production studies of oil palm plantings. For these types of calculations the time of canopy closure is also required, and can be derived from the curves of rachis length.

Acknowledgements. The patience of the field staff at Bah Lias Research is highly appreciated. They have been collecting data in these experiments for the last 14 years on a daily basis and still continue to do so. The permission of the board of directors of P.T.P.P. London Sumatra Indonesia to publish these data is acknowledged. Prof. dr ir J. Goudriaan, Prof. dr ir R. Rabbinge and Prof. dr ir M. Wessel are thanked for their criticism and comments on the various drafts of this manuscript.

\section{REFERENCES}

Anon (1982-1993). Bah Lias Research Station Technical Records 1982-1993, P.T.P.P. London Sumatra Indonesia, Medan.

Breure, C. J. (1982). Factors affecting yield and growth of oil palm tenera in West New Britain. Oléagineux 37:213-228.

Breure, C. J. (1985). Relevant factors associated with crown expansion in oil palm (Elaeis guineensis Jacq.) Euphytica 34:161-175.

Breure, C. J. (1988). The effect of palm age and planting density on the partitioning of assimilates in oil palm (Elaeis guineensis). Experimental Agriculture 24:53-66.

Broekmans, A. F. M. (1957). Growth, flowering and yield of the oil palm in Nigeria. Fournal of West African Intitution for Oil Palm Research 2(7):187-220.

Corley, R. H. V. (1973). Effects of plant density on growth and yield of oil palm. Experimental Agriculture 9:169-180.

Corley, R. H. V. \& Breure, C. J. (1981). Measurements in Oil Palm Experiments. Internal Report. Cambridge, UK: Unilever.

Corley, R. H. V. \& Gray, B. S. (1976). Growth and morphology. In Oil Palm Research, 7-21 (Eds R. H. V. Corley, J. J. Hardon \& B. J. Wood). Amsterdam: Elsevier.

Corley, R. H. V. \& Mol, C. K. (1972). Effects of nitrogen, phosphorus, potassium and magnesium on growth of oil palm. Experimental Agriculture 8:347-353.

Corley, R. H. V., Hew, C. K., Tam, T. K. \& Lo, K. K. (1973). Optimal spacing for oil palms. In Advances in Oil Palm Cultivation. The Proceeding of the International Oil Palm Conference held in Kuala Lumpur 16-18 November, 1972, 52-69 (Eds R. L. Wastie \& D. A. Earp). Kuala Lumpur, Malaysia: Incorporated Society of Planters.

Gray, B. S. (1969). A Study of the Influence of Genetic, Agronomic, and Environmental Factors on the Growth, Flowering and Bunch Production of the Oil Palm on the West Coast of Malaysia. PhD thesis, University of Aberdeen.

Hardon, J. J., Williams, C. N. \& Watson, I. (1969). Leaf area and yield in the oil palm in Malaya. Experimental Agriculture 5:25-32.

Henry, P. de (1957). Recherches sur la Croisance et le Dévelopment chez Elaeis guineensis Jacq. et chez Cocos nucifera L. Comparaisons avec quelques autres Palmiers. Thése, Faculté des Sciences de l'Université de Paris.

Keen, A., Thissen, J. T. N. M., Hoekstra, J. A. \& Jansen, J. (1989). Successive measurement experiments. Statistica Neerlandica 40:205-223.

Lecoustre, R. \& Jaeger, M. (1989). Modélisation de l'architecture et de la Géométrie d'Elaeis guineensis Jacq. Document No. 1, Laboratoire de Modélisation du GERDAT. Montpellier, France: Institute de Recherche pour les Huiles et Oléagineux. 
Lubis, A. (1984). Historis dan penelasan tentang bahan tanaman kelapa sawit. Pematang Siantar, Indonesia: Pusat Penelitian Marihat.

Phang, S., Ooi, C. H., Chan, K. W. \& Menon, C. M. (1977). Influence of soil series and soil depth on vegetative growth and yearly FFB production of the oil palm (Elaeis guineensis. Jacq.). In International Developments in Oil Palm, 153-166 (Eds D. A. Earp \& W. Newall). Kuala Lumpur: Incorporated Society of Planters.

Rao, V., Rajanaidu, N., Kushairi, A. \& Jalani, S. (1992). Density effects in the oil palm. In Yield Potential in the Oil Palm. Proceedings of the 1990 ISOPB International Workshop on Yield Potential in the Oil Palm, 71-79. Kuala Lumpur: Palm Oil Research Institute of Malaysia.

Rosenquist, E. (1986). The genetic basis of oil palm breeding populations. In Proceedings of the International Workshop on Oil Palm Germplasm Utilization, 27-56. Kuala Lumpur: Palm Oil Research Institute of Malaysia.

SAS (1985). SAS User's Guide: Statistics. Cary, NC, USA: SAS Institute.

Squire, G. R. (1986). A physiological analysis for oil palm trials. PORIM Bulletin 12:12-31.

Yampolski, C. (1922). A contribution to the study of the oil palm. Bulletin Fardin Botanique Buitenzorg. Serie 3 5:107-174. 